ENTREVISTA

\title{
TEORIAS DO SUL
}

Jean Comaroff

Em agosto de 2011, a antropóloga sulafricana Jean Comaroff - Bernard E. \& Ellen C. Sunny Distinguished Service Professor de Antropologia e Ciências Sociais da Universidade de Chicago - esteve no Rio de Janeiro para proferir a conferência de abertura do Seminário Internacional Cidades: Futuros Possíveis (PACC/UFRJ; Laboratório de Estudos Urbanos/CPDOC/ FGV, Núcleo de Estudos e Projetos da Cidade/PUC e Centro de Estudos de Segurança e Cidadania/UCAM). Nesse contexto, concedeu entrevista para Mariana Cavalcanti e Cláudio Pinheiro (pesquisadores do CPDOC/FGV) em torno de seus recentes interesses de pesquisa.

Jean Comaroff (PhD, LSE, 1974), um dos nomes mais relevantes da antropologia internacional, possui uma trajetória profissional bastante diversa. Acumula passagens por várias universidades entre África do Sul, Estados Unidos, Grã-Bretanha, França e Israel e uma ampla agenda de interesses - que incluem colonialismo e seus efeitos duráveis; práticas médicas, de saúde e corporais; evangelização cristã e lutas pela libertação no sul da África; formas de poder, rituais e estados de consciência; religião; juventude; fronteiras nacionais e fluxos migratórios; apartheid e pós-apartheid, entre tantos temas e tópicos de uma longa lista. Sua pesquisa de campo concentrouse prioritariamente na África do Sul, Botsuana e Inglaterra - entre os Tswana, da fronteira África do Sul-Botsuana-Zimbábue; os Barolong, da África do Sul-Botsuana; médicos e pacientes no sul de Gales; e famílias de pacientes de leucemia na Inglaterra.

Grande parte de seu trabalho é desenvolvido em parceria com seu marido, o também antropólogo John Comaroff, com quem publicou mais de uma dezena de artigos e livros em coautoria. Ao contrário de outros casais de intelectuais, os Comaroff não permitiram a subsunção da autoria ao gênero masculino e produziram uma obra variada e pujante ao longo de quase quarenta anos.

Ainda fortemente ligada a algumas das temáticas que orientaram sua carreira, Jean tem renovado seus interesses. Durante a última década vem lidando com o cruzamento de questões ligadas ao mundo jurídico e à polícia (leis, crimes e desordens) e à esfera pública, política e economia (populismo e neoliberalismo, governança e soberania nacional) em contextos pós-coloniais, o que tem ajudado a rever conexões entre modernidade, capitalismo e Estados nacionais, a partir de um enfoque antropológico, e que têm sido debatidas em campos como a ciência política. Essa agenda levou Jean e John a escreverem Theory from the South: Or, How Euro-America is Evolving Toward África, atualmente no prelo e com previsão de lançamento para novembro de 2011 (Boulder: Paradigm Publishers). 
O livro se enquadra em uma discussão que, se não é nova, vem ganhando renovada substância teórica nos quadros internacionais das ciências sociais: como se produzem teorias sociais de fora dos centros hegemônicos do pensamento - especialmente o que ficou conhecido como o Sul Global? De que maneira aportes teóricos desenvolvidos a partir de experiências histórias e sociais idiossincráticas da periferia podem renovar a pretensão universalista da antropologia, dando maior polifonia e renovando os paradigmas (reflexivos, teóricos e de categorias analíticas) das ciências sociais?

$O$ reconhecimento de que a antropologia partilha de uma episteme colonialista, marcada pelo caráter proselitista do conhecimento ocidental foi importante para a trajetória da disciplina. Diversos autores (E. Said, Talal Asad, E. Wallerstein, Partha Chatterjee, Claude Ake ou Dipesh Chakrabarty, entre tantos) sinalizaram para essa dimensão a partir da crítica a uma razão universal feita a partir da valorização da diferença e da diversidade o campo da pós-colonialidade, seus antecedentes e derivações.

Contribuições mais recentes, entretanto, ressaltam o esgotamento desse modelo (Alberto Moreiras) e procuram pensar novas pertinências e condições de relevância para as ciências sociais (Tim Quinlan, Syed Farid Alatas, Raewyn Connell, Eduardo Restrepo \& Arturo Escobar etc.) que reconheçam e incorporem a condição de periferia intelectual, de dependência na produção e na circulação internacional de conhecimento e suas consequências em aparatos semânticos e cognitivos acadêmicos ou não.

$\mathrm{Na}$ presente entrevista, Jean Comaroff se dispõe a observar a emergência de um quadro internacional amplo, no qual a reorganização de fluxos (humanos, de capitais e de conhecimento) expôs contextos do Norte a algumas das tensões que, historicamente, estruturaram sociedades coloniais e pós-coloniais do Sul: aquelas produzidas pela exposição à voracidade do capitalismo global. A diferença agora é que não apenas a circulação de capitais financeiros tem sido mais densa nas antigas periferias, como também a produção de teorias e a pluralidade de experiências de ação política dessas periferias passam a concorrer na revisão de paradigmas internacionais que equacionem a articulação entre modernidade, capitalismo e Estados nacionais. Isto aponta para um quadro em que não apenas teorias (econômicas, sociológicas etc.), mas as experiências da vida social se realizam fora da expectativa de organização do mundo social por padrões do Norte. 
Mariana Cavalcanti: Dez anos atrás, com os efeitos do 9/11, teria sido realmente admirável imaginar que em agosto 2011 estaríamos sobrevoando o Complexo do Alemão no recém-inaugurado teleférico, enquanto Londres era incendiada e os EUA faliam. O que essas mudanças e reviravoltas têm a ver com o seu Theory from the South (Teoria do Sul em tradução livre, ainda sem edição em português) $a$ ser lançado proximamente?

Acredito que uma das questões-chave que isso sugere é que, em muitos sentidos, houve uma inversão nos vetores para usar o modelo evolucionista - das formas que encontramos para pensar o "desenvolvimento". E aqui eu posso lembrar o subtítulo de meu livro com John Comaroff, que deve ser lançado em breve: "Como a Europa está evoluindo em direção à África". Usamos esta frase para provocar, para sugerir uma inversão do que podemos ter sido levados a esperar em relação ao télos da história e para tentar, como muitos fizeram antes de nós, desconstruir o pensamento da "Modernização" e suas premissas de maneira geral. O que um dia chamamos confortavelmente de "o sistema mundial" parece incrivelmente complicado agora: centros e periferias não apenas foram revertidos, mas também os nossos mapas estabelecidos de fronteiras e fluxos foram completamente abalados, com as movimentações, de maneira cada vez mais intensa e aparentemente indecifrável, de pessoas, imagens e capital por toda a extensão terrestre. É muito difícil, em meio a este movimento multidimensional, elaborar uma história simples e unilinear.

Mas em termos do que você me perguntou agora, por exemplo - como a natureza da vida urbana, Norte e Sul acho que olhamos para esses tipos de fe- nômenos sociais com outros olhos agora. E em parte isto acontece em função do que vemos em lugares como o Brasil especialmente aqueles que olham "com os olhos do Norte". Cidades nesse país expressam uma criatividade da concepção e da forma urbana, e uma vitalidade econômica que sobrepuja muito do que encontramos nas metrópoles europeias no presente; neste sentido, existe uma espécie de inversão na relação entre Brasil e Portugal, de maneira que a antiga colônia parece mais a metrópole. Vemos isto também no contexto africano, a respeito de Angola; muitos portugueses estão procurando trabalho na sua economia dinâmica.

Mas os nossos olhos estão diferentes agora em um sentido mais amplo. Quando olhamos para uma cidade agora, estamos pensando não em termos do grande design modernista da Paris de Hausmann, a metrópole europeia do fim do século XIX onde, ao menos na teoria, tudo era planejado em termos de desenho geométrico, com vias ordenadas e entrecruzadas e crescimento controlado, regulado por um planejamento racional, por meio de uma administração centralizada. Em especial nos contextos pós-coloniais, o crescimento e a direção das cidades escapam ao planejamento civil centralizado, superando as formas urbanas mais antigas e as provisões municipais limitadas. Com o aceleramento da urbanização por todo o planeta, a expansão da cidade está muito mais nas mãos de pessoas comuns, que buscam fazer dela um lugar seu, que sentem ter direito a ela, que veem qualquer futuro como dependente de viver nela, e que podem inclusive "invadir" seus espaços ilegalmente se for necessário. As pessoas fazem habitações nas cidades em que - e com o que - podem. Elas remodelam formas existentes já construídas, 
subdividem-nas e intensificam-nas, ou constroem seus próprios assentamentos informais no espaço disponível. Tudo isso torna a cidade muito menos previsível do que era, pelo menos em sua concepção automodernista: é mais difícil de mapear, caracterizar e servir. Nosso modelo de cidade tornou-se imensamente flexível. Também teve que se reconhecer o fato de que, nos tempos atuais, a relação entre cidade e Estado foi alterada, tal como a relação do Estado-nação com a economia nacional. Em grande parte do mundo (e aqui a América Latina pode ser uma das exceções) não esperamos mais que grandes governos dirijam o desenvolvimento nacional. As cidades são mais nitidamente expressões de empreendimentos desregulados e forças de mercado.

Tudo isso significa que estamos olhando para as cidades contemporâneas com olhos diferentes, e estamos começando a ver lugares que antes eram periferias como fronteiras. Cidades no Sul, muitas construídas em condições coloniais, desde há muito tempo tenderam a escapar dos planos imperiais de ordenálas com pequenos núcleos administrativos e grandes periferias desordenadas. Em sua inventividade, flexibilidade e capacidade de se adaptar a populações e a economias em constante mudança, elas sempre estiveram à frente da metrópole europeia, mais formal. E elas são fronteiras também devido às mudanças mais recentes na natureza do capitalismo de escala mundial. O próprio capitalismo moveu suas fronteiras de operação para o que antes eram margens - lugares como Brasil, China, Singapura, África do Sul e Índia. Em grande medida, isto aconteceu em razão da competição cada vez mais global por mão de obra mais barata e menos restrições à operação, a agora consolidada história da terceirização rentável a partir dos antigos centros.
Mas muitas "periferias" mais antigas (e o Brasil entre elas) se tornaram agora centros econômicos poderosos em escala global, provendo abordagens dinâmicas e flexíveis em relação à produção, encontrando nichos inovadores em mercados existentes - como o da indústria do biocombustível. Elas também desenvolveram abordagens experimentais para os problemas urgentes da sociedade capitalista recente - como os abismos mais e mais amplos entre riqueza e pobreza, a natureza em transformação do trabalho (que se parece cada vez menos com o trabalho assalariado formal e levanta enormes problemas de desemprego); penso em novas estratégias, como o Bolsa Família, desenvolvido no Brasil, que têm chamado a atenção do mundo.

Esta não é uma história de todo positiva, pois a razão pela qual o capital na sua forma atual parece prosperar nas antigas periferias é que seus antigos centros - os Estados industriais do Norte - se tornaram menos e menos hospitaleiros à rentabilidade competitiva, quando os trabalhadores ao longo do século XX foram progressivamente adquirindo direitos a condições de trabalho adequadas, igualdade de salários entre gêneros e raças, e quando os Estados de bem-estar estenderam a redistribuição de recursos e o fornecimento de serviços às suas populações, o que envolveu a regulamentação e a taxação de capital e corporações que operavam em seus domínios. Depois da Segunda Guerra Mundial, que estimulou a integração global e a operação competitiva do capital em países de avançado desenvolvimento industrial, os donos desse capital começaram a procurar por condições de produção mais baratas e maleáveis "além-fronteiras", com isso driblando a regulamentação do Estado e globalizando a divisão do trabalho como nunca antes. Também havia uma tendên- 
cia, no Norte, de se despojar da produção industrial como um todo para enveredar pelas operações de capital financeiro. Muito do crescimento econômico que foi possibilitado nas novas fronteiras do capital - a captura de iniciativas nas indústrias de aço e automóveis na Índia, por exemplo, ou a expansão da manufatura de maneira geral na China ou na Tailândia - se deve ao fato de que esses lugares ofereciam condições de trabalho menos reguladas e mão de obra mais explorável. Enquanto isso, em muitos países do Norte, a desindustrialização trouxe o crescente desemprego e Estados de bemestar começaram a se contrair, enquanto as ideologias neoliberais ganhavam terreno como o novo mantra para combater as tragédias econômicas. E os cidadãos do Norte começaram a experimentar o tipo de precariedade que há muito era comum em muitas pós-colônias.

Então essa história longa e cheia de desdobramentos subjaz entre as causas para muitas cidades no Sul parecerem agora mais vibrantes econômica, política e culturalmente do que grande número de centros robustos do Norte, onde cidadãos começam a protestar com eloquência contra o desemprego, as medidas de austeridade e a redução nas provisões estatais - os tipos de conflitos que vimos nas ruas das cidades inglesas no último verão. E compreender tudo isso requer que entendamos o que aconteceu com a natureza do capital sob as condições atuais (aquilo que muito frequentemente glosamos como "neoliberalismo" ou "globalização", mas que é parte de uma história mais complicada). É uma história que assistiu à reordenação do capital em escala global e, com ela, uma expressiva mudança na relação entre economia e regime político, entre os empreendimentos capitalistas e o Estado-nação tal como existia na alta modernidade.
Ironicamente, as condições existentes no final do século XX em países frequentemente chamados "pós-coloniais", condições estas muitas vezes lamentadas pelos observadores ocidentais - como o alto nível de informalidade econômica, a regulamentação estatal limitada ao empreendimento corporativo e o mirrado desenvolvimento dos direitos dos trabalhadores - tornaram-nos ainda mais propícios ao florescimento do capitalismo nesta fase atual. A África, nos últimos anos, mais uma vez se tornou uma zona promissora de investimento. E ali encontramos populações que há muito foram levadas a desenvolver maneiras de viver em circunstâncias precárias, a conceber os meios de sobreviver em condições de aparente impossibilidade, a inventar novos modos de ganhar dinheiro a partir do nada - algo com que os europeus, agora enfrentando crises econômicas sem precedentes, tiveram pouca prática. De súbito, em muitos sentidos, a África se parece com uma fronteira e a Europa parece pós-colonial - pessoas vivendo nas ruas e a juventude provocando tumultos em protesto. E enquanto isso, muitos formuladores de políticas e analistas estão olhando para lugares como Índia e Brasil atrás de modelos para entender a cidade moderna mais recente. O que costumava ser a marca arquetípica do Terceiro Mundo subdesenvolvido - a miséria das pessoas que invadiam centros urbanos e erguiam assentamentos informais e favelas - agora parece mais familiar. Essas formas urbanas sugerem novos tipos de inevitabilidades que podem também oferecer novas possibilidades, como a moradia flexível, construída informalmente, que emerge das necessidades criadas pelas condições de vida atuais e evidencia a insistência das populações em seu direito a uma existência urbana e civil. Estas são cidades que respondem 
a economias urbanas em transformação, a demandas por trabalho em transformação, a condições em modificação da vida doméstica.

Cláudio Pinheiro: Avançando nessa inversão do equilíbrio de poder entre antigas colônias e ex-metrópoles, você diria que lugares como os trazidos pela África do Sul, a Índia ou o Brasil realmente sugerem novas teorias do desenvolvimento, ou estão apenas copiando essa pauta de desenvolvimento que estrutura a divisão entre países ricos e pobres ou entre Norte e Sul? Estamos apenas invertendo essa pauta, mas usando a mesma gramática de poder?

Não creio que seja a mesma gramática, e explicarei porque penso que não seja este o caso. O fim da Guerra Fria (que, aliás, nenhum de nós, cientistas sociais, previu, ou compreende plenamente mesmo agora) pode ter sido aclamado por muitos como o triunfo final da "liberdade" de mercado em todo o mundo. Mas logo se tornou visível que ele também marcou o fim do ideal de modernização como possibilidade infinita e progresso sem fim, em que cada geração viveria melhor que a anterior, com Estados soberanos gerindo suas próprias economias nacionais e cuidando, em grande medida, de mitigar as crises econômicas catastróficas, e assim por diante. O que acontece agora é que, no alvorecer da expansão de modelos liberalizados de mercado, no aperto da integração global fiscal e na globalização da divisão do trabalho, existem poucos lugares que escapam dos efeitos da produção capitalista e de suas formas culturais, embora as maneiras efetivas pelas quais eles tomem forma em diferentes lugares variem de acordo com as condições locais históricas e sociais, e com a localização em um mapa global geopolítico.
O que caracteriza as condições atuais como diferentes das da alta modernidade que as antecederam é o grau em que o capital e suas corporações conseguiram se ver livres do controle do Estado-nação. O capital usa o espaço do Estado-nação e tende a confiar na sua regulamentação pacificadora e contratual. Frequentemente, para atrair o investimento móvel global, os Estados concedem às corporações e aos investidores externos soberania considerável - eles muitas vezes suspendem leis ambientais e leis que regulam o emprego em seus domínios, por exemplo. Eles também são excessivamente relutantes em cobrar impostos das corporações (mesmo quando a economia irlandesa perdeu o chão recentemente, houve forte relutância em elevar o imposto das corporações globais, temendo que estas últimas pudessem buscar condições mais favoráveis em outras partes). As corporações, nessas condições, têm pouca fidelidade ou responsabilidade, embora os Estados tenham se tornado tão dependentes de seus investimentos que pagarão enormes quantias para afiançálas, caso fracassem.

Tudo isso não significa que os Estados tenham se tornado irrelevantes. Em muitas das economias atuais mais vibrantes do mundo - Rússia e China o próprio Estado se tornou corporativo e administra os empreendimentos nacionais de forma eficiente e competitiva em escala global. Em outros contextos, como diversos países latino-americanos, houve manobras para fortalecer o Estado como mediador entre as economias nacionais, os recursos e as ávidas corporações globais. De fato, países como o Brasil e também a África do Sul apresentam sínteses fascinantes entre instituições econômicas centralizadas e empreendimentos de mercado liberais, mesclando programas de redistribuição social de larga escala 
com técnicas e idiomas de neoliberalismo. Aqui, para voltar à sua questão, não estamos apenas copiando a história e a gramática do desenvolvimento do Norte no Sul, porque as condições históricas locais e a própria natureza do capitalismo estão numa fase diferente, com consequências sociais e culturais significativas. Em muitas antigas colônias pobres, a imposição de Programas de Ajuste Estrutural e da política de "livre mercado" abriu economias nacionais frágeis a investidores externos e a forças de trabalho imigrantes dispostas a reduzir os custos do trabalho local - esgotando os recursos nacionais e aumentando a distância entre ricos e pobres. Mesmo em economias mais robustas do Sul, a intensificação do crescimento capitalista foi acompanhada pela ampliação do Coeficiente de Gini, a redução de barreiras comerciais e a perda da soberania econômica nacional. Em suma, o desenvolvimento de novos centros de poder econômico, como Brasil, Índia e África do Sul, aconteceu em uma economia global que é diferente, em aspectos-chave, da antiga ordem internacional. Isto tem implicações para a sociologia interna dos Estados-nação a natureza das relações de classe, dos padrões de identidade e da natureza da política. Classes médias ficam ameaçadas em muitas situações como essas, por exemplo, e as identidades baseadas na posição que se ocupa na divisão de trabalho deram lugar àquelas baseadas em marcadores, como etnia. O desemprego em massa e a descartabilidade também se inclinam a ser decorrências desses novos arranjos, que tendem a erodir as formas modernistas de trabalho em favor de outros tipos de produção baseados na mercantilização de conhecimento e serviços, ou o uso de dinheiro para gerar dinheiro. Tudo isso conduz àquilo que comumente se denomina "crescimento sem emprego", e significa que gerações inteiras estão atingindo a idade adulta sem grandes perspectivas de ter um emprego "propriamente dito". De fato, divisores geracionais estão se tornando tão acentuados como um dia aconteceu com a classe. Tais condições geraram novas formas de política, novos objetos de disputa (como o direito à moradia, à renda mínima, a trabalho e a acesso à cidade). E novas formas de acomodação informal - os arranjos urbanos flexíveis de que falamos acima. Então, a mudança em direção ao Sul das fronteiras energéticas do capital não é apenas uma reversão. E estes novos modos de produção apresentam traços bastante perturbadores: a desintegração do contrato de trabalho como vínhamos conhecendo nas democracias avançadas modernas e a intensificação da espoliação do meio ambiente. O capital, em seu disfarce mais recente e globalmente competitivo, limitou o uso para instituições democráticas, contanto que seus ativos estejam protegidos. Mas o outro lado disso tudo é o advento de novas formas de discordância e disputa, novos movimentos sociais - desde alegações baseadas em direito à cidadania até invasões de terra e apropriações; reivindicações por serviços básicos e/ou os meios para a sobrevivência digna - o que na África do Sul se denomina "política de vida". E isto aconteceu em conjunção com o surgimento de tecnologias novas, populares e acessíveis de comunicação que tendem a fugir ao controle fácil de cima para baixo. O advento das mídias sociais, que operam interativamente e em muitos níveis e escalas, serve para criar sujeitos, públicos e modos de mobilização. E estamos apenas começando a entender as implicações dessas tecnologias, que têm consequências menos previsíveis do que muita gente pensou num primeiro momento. Houve a Prima- 
vera Árabe, sem dúvida, e essas mídias municiaram mobilizações paralelas em outros lugares por serviços básicos, moradia e direitos dos cidadãos. É possível perceber as possibilidades democratizantes da internet com as redes sociais eletrônicas e outras formas de mídias sociais. Mas também testemunhamos a sua capacidade de amplificar orientações desagregadoras, violentas e até mesmo fascistas - como a cruzada em defesa de uma Europa Cristã por parte do ativista de direita Anders Behring Breivik, que aconteceu em Oslo, no último verão.

A chamada "ordem global" fica muito diferente nesta conjuntura. E muitos dos traços que foram aparentes por algum tempo no Brasil, na África do Sul e na Índia estão agora se manifestando em países do Norte, que estão parecendo cada vez mais pós-coloniais. Em póscolônias, as identidades nacionais sempre existiram em tensão com afiliações étnicas (isto era muitas vezes visto como tribalismo ou comunalismo imaturo por observadores do Norte). Mas tais afiliações são agora cada vez mais evidentes nos Estados-nação europeus, que se parecem cada vez menos com as comunidades imaginadas homogêneas de Benedict Anderson. Isto não se deve meramente à imigração intensiva, um dia encorajada e agora cada vez mais ressentida, mas também ao fato de que estes mesmos Estados-nação frequentemente não podem mais evocar a adesão explícita de seus cidadãos como um dia o fizeram, quando eles representavam verdadeiramente o bem público com soberania políticoeconômica. Mas quaisquer que sejam as causas, os Estados europeus tiveram que progressivamente reconciliar sua suposta homogeneidade com as realidades da diferença. No Reino Unido, o Arcebispo de Canterbury sustentou recentementede forma altamente controversa, sem dúvida - que os muçulmanos britânicos deveriam ter o direito de escolher ser governados em algumas esferas (em relação a disputas conjugais, por exemplo) pela sharia. Desta forma, também, os Estados do Norte estão parecendo mais pós-colônias, e novamente vemos que o momento atual não é simplesmente uma reprodução do passado do Norte no presente do Sul.

MC: Como isso se dá em termos de política acadêmica? Ficam preservadas as relações de poder que perduraram por tanto tempo, ou seja, o Norte produzindo teorias e o Sul consumindo-as?

Estas mudanças não se dão simultaneamente, como se o processo social e a teoria social fossem coligadas. Há atrasos, voltas, anacronismos. Vejamos a oposição Norte-Sul. Acredito que é preciso tanto reconhecer que esse dualismo tem algum proveito analiticamente (por certo tem alguma realidade no mundo, afinal de contas), como também desconfiar muito da oposição, empenhar-se - de fato - em desconstruí-la no fim das contas. Mover-se para além dela, para o conjunto mais amplo de condições que deu sustentação a ela e perpetuou o seu uso. Consideremos, por um momento, a longa história de como as pessoas no Norte, e não menos na academia, conceberam e agiram em relação a algo que variadamente se chamou de o "não Ocidente", o "Terceiro Mundo" e, mais recentemente, o "Sul Global". Enquanto o advento das ciências sociais no final do século XIX tende a ser localizado com solidez na Europa, estas formas de conhecimento sempre se debruçaram de forma central no talento e na perspicácia daqueles para além de sua aparente terra natal. Inicialmente, vindos da periferia "oriental" e de elites coloniais - intelectuais do 
Leste Europeu, judeus e classes cultivadas das várias periferias imperiais. Ao olharmos para a antropologia britânica do início do século $\mathrm{XX}$, foram essas elites migrantes e marginais que constituíram a maior parte de sua geração fundadora figuras como Malinowski (um membro deslocado das classes altas polonesas), muitos estudiosos sul-africanos, vários deles judeus, e muitos jovens pensadores brilhantes da Nova Zelândia, da Índia, e assim por diante. Eles foram cruciais na modelagem da disciplina em seus primeiros anos. Na época em que cheguei à London School of Economics (Faculdade de Economia e Ciência Política de Londres), no final dos anos 1960, em um momento em que era um centro ativo para se repensarem as ciências sociais numa época de agitação global, o lugar abundava em estudantes vindos do que em breve passaríamos a chamar "póscolônias", pessoas treinadas em escolas coloniais de elite, mas com sensibilidades que se estendiam para além do alcance das hegemonias europeias, pessoas que tinham experimentado em primeira mão as contradições da "missão civilizadora" europeia. Na nossa disciplina, temos importado trabalho e talento intelectual do Sul por um longo período de tempo, naturalizando estudiosos estrangeiros e patenteando suas ideias. Eu me lembro de Benedict Anderson dizendo que a Academia norte-americana era especialista em colocar o seu selo na criatividade intelectual que canibalizava de outros lugares. [Risos]

Então, desde o princípio, a distinção Ocidente/não Ocidente, Norte / Sul tem sido mais uma ficção do que um fato. A modernidade europeia, o surgimento do modelo do Estado-nação e da ordem econômica industrial-capitalista em que se apoiava foram sempre construídos extraindo valor e inspiração do
Sul - suas matérias-primas, sua força de trabalho, sua criatividade cultural. Metrópoles e colônias eram condições de possibilidade uma da outra, como partes semelhantes (embora desiguais e internamente divididas) de entidades sociais e econômicas. A África do Sul e a Índia colonial eram, nesse sentido, partes do Estado-nação britânico em tudo, menos o nome - eram o seu quintal, seus bastidores. O que a Europa alegava ser seu era muito frequentemente apanhado em suas "periferias" imperiais, ou ao menos o produto de uma dialética material, política e cultural permanente com elas. Mas o centro da história, da civilização, do progresso permanecia fixado firmemente na Europa (usada aqui no sentido de Euro-América). E embora tenha havido mudanças consideráveis como as que estamos discutindo, na orientação centro-periferia do mundo pós-colonial, a hegemonia intelectual do conhecimento acadêmico e científico permanece com relativa segurança no Norte - especialmente no âmbito do Norte anglófono. Os Estados Unidos podem estar de joelhos economicamente, mas Harvard ainda é considerada a universidade número um mundialmente. E o "reconhecimento" global ainda reside com bastante força no crédito outorgado pelas academias, pelos periódicos e assim por diante da Euro-América (embora as instituições norte-americanas tenham progressivamente ultrapassado as europeias neste aspecto).

Assim, enquanto a Europa se tornou descentralizada, provinciana, no nosso mundo atual, sob muitos aspectos, persiste uma percepção de que o trabalho "teórico" de relevância global é feito no Norte; que o Sul é fonte de "dados", "matéria-prima", ideias locais. Ao mesmo tempo, os que somos privilegiados para poder circular entre o Norte e o Sul 
com regularidade logo aprendemos que muito do que está sendo debatido em universidades e fóruns públicos intelectuais do Sul é mais dinâmico, de ponta, inovador do que o que está acontecendo nos contextos equivalentes do "velho mundo". Isto encontra paralelo com o que dizíamos sobre a vida urbana e suas formas. Os assuntos são frequentemente mais imediatos e urgentes nas novas fronteiras e lá as pessoas vivem há muito tempo de forma imediata e aguda com as contradições do mundo moderno - a distância entre o que ele promete e o que proporciona. Se visitarmos universidades da América Latina, ou da Índia, ou da África do Sul, veremos que o debate é incrivelmente vivaz. Estudiosos estão menos interessados nas últimas preocupações em Londres ou Nova York e mais imbuídos da compreensão de que os ponteiros para o futuro e a necessidade de engendrar maneiras de lidar com ele estão bem aqui, no Sul. Ao mesmo tempo, e a despeito disto tudo, perdura certo encolhimento do Sul, uma sensação de que, com toda a sua excitação e criatividade, os estudiosos do Sul ainda não estão propriamente sendo levados a sério no Norte - ao menos não como estudiosos capazes de oferecer teorias ou lampejos de importância "universal".

CP: Você retratou um mundo em movimento, arrebatado por mudanças em termos políticos e intelectuais. Mas no que diz respeito à antropologia, trata-se de uma disciplina que nasceu do projeto de uma civilização para reforçar a celebração da alteridade. Como pode a antropologia ser universalmente válida nos dias atuais - como um projeto para entender a alteridade?

A antropologia sempre manteve a pretensão - e não estava de todo equivocada - de que era, acima de tudo, uma disciplina empírica, isto é, o conhecimento derivava da observação ordenada dos "fatos consumados". Começava-se por olhar para esses fatos em um lugar, um ponto social, examinava-se o entorno e construíam-se teorias totalizantes com base naquilo que se via em termos da estrutura e da operação de sociedades ou culturas particulares. De certa forma, a perícia da disciplina, seu senso de originalidade única, advinha do fato de que nos permitíamos pensar que estávamos inventando uma ciência social distinta, não ocidental, ex nihilo. Afinal de contas, estávamos indo a lugares e observando formas de vida coletiva às quais nenhuma sabedoria acumulada do pensamento social ocidental se aplicava, certo? Então, éramos uma disciplina moderna, empírica, indo atrás de estudar sociedades que apresentavam desafios únicos à ciência social estabelecida, porque eram diferentes das sociedades e das culturas da Europa; sociedades que também aparentemente - não tinham nenhuma história própria escrita. E, investindo pesado na analogia orgânica, fomos em busca de estudá-las como sistemas nítidos, empiricamente observáveis no mundo. Fomos estudar "os habitantes das Ilhas Trobriand", ou os "tswanas", como entidades autoperpetuadas, descontextualizadas do passado e do presente mais amplos dos quais provinham - incluindo o mundo colonial que os tornara acessíveis à pesquisa de campo em primeiro lugar. Supúnhamos que podíamos vêlos por todos os ângulos, como sistemas totais, e que nossas descrições deles, as teorias que desenvolvemos sobre sua organização e modo de funcionar eram sui generis, distintas dos modelos e das preocupações da corrente principal das ciências sociais ocidentais. Mas na realidade (acabo de escrever a respeito 
disso), quando você observa as ideias de Evans-Pritchard, Radcliffe-Brown ou Malinowski, elas devem muito às constantes preocupações do pensamento e da sociedade ocidental daquele período. Estes estudiosos estavam lendo Durkheim, Freud e Marx, juristas comparativos como Henry Maine e evolucionistas sociais como Herbert Spencer. E viviam em um mundo europeu arrasado pela guerra e preocupado com os problemas da ordem social. E carregavam muitas dessas angústias com eles para o seu estudo das sociedades "não europeias", que frequentemente pareciam não tanto inversões da civilização ocidental, mas modelos elementares precisamente da ordem social, da coesão moral e da autoperpetuação de que a Europa moderna parecia carecer. Se observarmos o prefácio de Radcliffe-Brown para Sistemas políticos africanos, ele começa por afirmar que a antropologia social procura construir conhecimento sistêmico sobre o não Ocidente com base na observação e na comparação de sociedades às quais a filosofia política ocidental não se aplica. Em seguida se contradiz, ao usar justamente esse conhecimento não ocidental para repensar algumas das questões fundamentais da teoria política europeia - questões como se, de fato, existiriam os "Estados soberanos", ou se seriam mera ficção dos filósofos. E prossegue com declarações bastante profundas - como o fato de que, na verdade, não existe um Estado abstrato, com uma "vontade" para a ação, e assim por diante; tudo que realmente existe no mundo são constelações de instituições sólidas empreendendo os interesses do governo.

Ora, Radcliffe-Brown está se permitindo falar, aqui, como um filósofo para a ciência social em geral a partir do ponto de vista da antropologia como ciência comparativa. E ele está oferecen- do um conjunto de proposições teóricas baseadas, em parte, na etnografia das sociedades não ocidentais e, em parte, na sua reflexão acerca delas, à luz de um conjunto de inquietações mais gerais sobre a sociedade tout court. E ele está teorizando muito além dos seus "dados" sobre questões centrais para as preocupações da ciência social ocidental. Sempre nos pensamos como uma disciplina indutiva, mas sempre também pegamos ideias europeias e as colocamos para funcionar em "outros" lugares. Como poderia ter sido de outra forma? E sempre nos envolvemos naquilo que Edmund Leach chamou de "suposição inspirada", provocada pelo tipo de deslocamento, o estranhamento proporcionado pelo nosso método, que buscava relativizar as hipóteses europeias, mas que apenas poderia conseguir isto em um grau imperfeito.

É evidente que, em nosso esforço de valorizar e aprender com a alteridade, sempre tendemos a simplificar os nossos objetos. Isto foi particularmente verdadeiro durante os primeiros anos do funcionalismo estrutural, com a sua pretensão de que seria possível isolar e delimitar sociedades "simples" para fins de análise. Esse tratamento restritivo, homogeneizador, era também um traço das perspectivas mais culturalistas e hermenêuticas. E embora tenha havido movimentos em direção à complexificação de nossas visões de sociedade e cultura, a fim de situar nossas unidades de análise no mundo mais amplo, certa simplificação persiste. É um problema inerente a todas as formas de abstração e análise. Mas o holismo que era característico dos primeiros tempos da antropologia tinha algumas vantagens: ele nos dava a habilidade (alguns diriam a hubris) de desenvolver "grandes ideias", de generalizar de uma forma que era sempre tanto indutiva quanto dedutiva. A antropologia 
desenvolveu inspirações audaciosas sobre a operação da vida e do pensamento humano que têm sido de continuado valor para as ciências humanas (desde teorias sobre brincadeira, poluição, ritual e sacrifício a modelos de classificação, trocas, dinheiro). E isto sempre envolveu debruçar-se de forma criativa em ideias e exemplos para além de nosso campo imediato de estudos e repertório de conceitos. Fazemos as perguntas complicadas sobre por que os fenômenos sociais assumem as formas que assumem em tempos e lugares específicos, sobre a intrigante relação entre semelhança e diferença. A iniciativa, em outras palavras, nunca foi meramente uma questão de "entender a alteridade".

\section{CP: Então, como descolonizar essa agenda?}

Esta é uma questão-chave, e uma questão que precisa ser formulada a partir de muitos contextos de produção antropológica. O Brasil tem um papel-chave a desempenhar aqui, por ter sido sempre um local de importantes pesquisas antropológicas, e que tem uma das maiores comunidades de antropólogos em atividade no mundo. Uma das maneiras de pensar essa questão é voltar à própria história da disciplina, e examinar suas capacidades internas para a reflexão crítica e a transformação. Vejamos o exemplo da antropologia britânica: começamos com essa ideia de estudar sociedades simples como pequenas ilhas, como modelos orgânicos de ordem e normatividade autorreproduzida. Seu equilíbrio durkheimiano para a primeira geração, em sua maior parte, foi auxiliado pelo fato de que muitos profissionais de fato trabalhavam em sociedades insulares. Mas, na geração seguinte, muitos estudiosos vão para a África Central. Em primeiro lugar, encontram sociedades matriarcais, um tanto quanto diferentes das ideias recebidas, e patriarcais de ordem. Em segundo lugar, estão em um local onde não se pode sequer romancear, tratá-las de sociedades discretas, ou que sejam ordenadas, porque as comunidades locais abundam em tensão, e se decompõem diante dos nossos olhos. E mais do que isso, o mundo colonial britânico está tão presente que é inescapável: grande parte da vida cotidiana é monetarizada, e as pessoas migram como assalariadas para os centros de indústrias coloniais. Então, você diz a si mesmo: "aonde vamos, então, para entender isto"? Nossos cânones existentes não são suficientes, em especial o legado de Durkheim com a sua ênfase na ordem funcional. No caso da chamada Escola de Manchester na África Central, estudiosos confrontando essas realidades começaram a ler a literatura mais ampla da ciência social. Começaram, por exemplo, a ler Marx (uma das figuras de liderança deste grupo, Max Gluckman, crescera na África do Sul, observara de perto as fervilhantes tensões daquela sociedade e estudara o pensamento marxista). Então, ele pegou do marxismo certos insights-chave sobre tensão, conflito e contradição, e ele e seus colegas se puseram a complexificar modelos recebidos de reprodução social simples ao argumentarem que a sociedade que eles observavam produzia conflito e ambiguidade tanto quanto regularidade normativa; que a vida social era um processo no qual atores buscavam ganhar suas vidas gerindo esses conflitos recorrentes, algumas vezes produzindo a ordem, outras, a ruptura social, sendo ambas possibilidades estruturais sob condições dominantes. Essas condições envolviam o confronto de sociedades "tribais" e forças coloniais que eram campos simples e, no total, sociais. 
Agora, embora esses analistas não tenham ido tão longe como para inventar uma antropologia do colonialismo eles ainda investiram em provar que as sociedades tradicionais mantinham sua integridade essencial, mesmo sob o impacto de forças coloniais e relações de mercado - eles contribuíram enormemente para abrir as perspectivas de seu tempo. Seus objetos de estudo incluíam as operações de colonizadores, mercados de trabalho migrantes, dinheiro, urbanização e relações étnicas. E de forma a empreender esses objetos, eles divisaram novas e inovadoras metodologias, como o uso inicial da análise em rede (porque as comunidades urbanas e os trabalhadores instáveis não podiam ser simplesmente observados em termos diretos, cara a cara). Então, vê-se como, em sua efetiva operação, mesmo a antropologia colonial começou a se descolonizar de formas importantes ao confrontar as contradições em sua própria prática. E devemos continuar a agir de modo semelhante, ainda mais vigorosa e cautelosamente: como os paradoxos de ideias e métodos recebidos podem se adequar ao mundo que procuramos compreender? Como podemos torná-los mais apropriados aos desafios daquele mundo? Aonde devemos ir para buscar inspiração e renovação intelectual?

\section{CP: Você gostaria de dizer alguma coisa} sobre o livro - Theory from the South: How Euro-America is Evolving toward Africa (Teoria do Sul: como a Euro-América está evoluindo em direção à África) que você e John Comaroff estão prestes a lançar? Sairá em novembro próximo, não é?

É uma reunião de ensaios, cada um deles escrito bastante recentemente, cada um centrado em um fenômeno específico que se manifestava, em primeira instância, na África do Sul, mas que estava também evidente no continente e no mundo mais amplo. John Comaroff e eu sempre pensamos a África do Sul tanto como um local em si mesmo (o lugar de onde por acaso somos) e também como um portal para um mundo mais extenso. E acontece que a África do Sul é um lugar muito efetivo a partir do qual se pode pensar esse mundo mais vasto, porque acaba por sintetizar tantos dos paradoxos e das promessas de nossos tempos - seja em termos de colonialismo, do Estado racial, da transição para a democracia, do papel dos líderes épicos, das possibilidades de justiça corretiva, seja do crime, da corrupção ou da xenofobia. Então, é um contexto instrutivo em termos do que pensar sobre muitos dos enigmas do mundo moderno recente.

O livro procura refletir sobre esses enigmas com o contexto de Theory from the South (Teoria do Sul) que vimos discutindo, e procura explorar essa tese por meio de uma série de ocorrências e questões sociais, cada uma das quais esperando oferecer lampejos surpreendentes para questões muito gerais "do Sul", por assim dizer. Os ensaios também tentam mostrar como, em muitos sentidos, os processos em exame são presságios de processos mundiais mais amplos em formação. Ao tocar em uma gama de temas - direito, trabalho, pessoalidade, nações e limites territoriais, a política da natureza e os contornos do capitalismo contemporâneo - procuramos perguntar como poderemos entender estas coisas com uma teoria desenvolvida a partir de uma acomodação "ex-cêntrica". Esta visão, esperamos, tornará alguns problemas centrais de nossa época estranhos e familiares ao mesmo tempo, proporcionando uma irônica virada nos caminhos evolucionários há muito ado- 
tados pelos cientistas sociais da corrente predominante.

Então, cada um dos ensaios no livro começa com algo revelador sobre os nossos tempos atuais que se tenha feito sentir de forma mais urgente e visível no Sul e, em seguida, passa a mostrar como esses fenômenos poderiam ser lidos como prefigurações de coisas que estão acontecendo em outras partes. A África do Sul é um contexto efetivo para um exercício deste tipo, não apenas por seu lugar na atual imaginação global, mas também porque se tornou uma fronteira de certa forma.

Os tipos de questões com que demos início a esta conversa - as favelas e sua projeção urbana - me arrebatam, de uma maneira semelhante, como exemplares - como focos ricos para se pensar o problema do planejamento urbano no nosso momento histórico atual. É fácil, ao fazê-lo, romantizar a pobreza, a privação e a violência tão prevalecentes em muitos pontos do Sul. Mas há muito mais em jogo aqui, pelas razões que discutimos acima. Para mim, essas formas de existência urbana asseveram o direito de seus habitantes de fazerem parte da conversa global sobre cidades, cidadania e a participação de tipo político, cultural e econômico. E, dado o estado das cidades por toda parte, essas comunidades (e percebo que não são todas iguais; que variam em condições de vida e possibilidade) repentinamente parecem muito avant garde. Elas não podem mais ser vistas meramente como desvios de um plano mais racional, como aberrações temporárias ou escândalos do Terceiro Mundo. Estes são precisamente os tipos de exemplo que o nosso livro procura analisar.

Transcrição de Thaddeus Blanchette Tradução de Fernanda Guimarães 